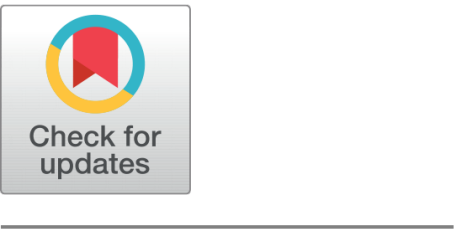

OPEN ACCESS

Received: 09.07.2020

Accepted: 26.09 .2020

Published: 09.10.2020

Editor: Dr. Natarajan Gajendran

Citation: Patel GB, Shah KR (2020) Isolation, screening and identification of Lipase producing fungi from cotton seed soapstock. Indian Journal of Science and Technology 13(36): 3762-3771. https ://doi.org/10.17485/IJST/v13i36.1099

*Corresponding author.

hisonu2408@yahoo.co.in

Funding: None

Competing Interests: None

Copyright: @ 2020 Patel \& Shah. This is an open access article distributed under the terms of the Creative Commons Attribution License, which permits unrestricted use, distribution, and reproduction in any medium, provided the original author and source are credited.

Published By Indian Society for Education and Environment (iSee)

ISSN

Print: 0974-6846

Electronic: 0974-5645

\section{Isolation, screening and identification of Lipase producing fungi from cotton seed soapstock}

\author{
Gayatriben B Patel ${ }^{1 *}$, Kamlesh R Shah ${ }^{1}$ \\ 1 Department of Biotechnology, Pramukh swami science, and H.D. Patel Arts College, Kadi, \\ India
}

\section{Abstract}

Background/Objectives: The present study was focused to exploit the indigenous strains of fungi isolated from cotton seed soapstock for the production of the extracellular lipase through submerged fermentation technique. Methods/ Statistical analysis: Cotton seed soapstock samples used in the study contains gelatinous oil richer chemical constituents. In addition, their enrichment and diluted materials were used for the isolation of lipase producing microorganisms on tributyrin agar plates. All isolates were lipase positive confirmed by a qualitative plate assay. Quantitative estimation of Lipase production activity was measured spectrophotometrically using $p$ nitrophenyl palmitate ( $p$-NPP) as a substrate. In order to exploit the isolated fungal strain for industrial usage, other cellulase and protease enzymes were tested by plate assay. Morphological and molecular characteristics of selected isolates were studied. Findings: From enriched soapstock samples, a total of 49 cultures were isolated among them 19 fungal isolates were screened for lipase, cellulase, and protease activity qualitatively by plate assay. Out of 19, six fungi were selected based on their lipase activity. Highly potent Fusarium solani 7F had the ability to produce $5.95 \mathrm{U} / \mathrm{mL} / \mathrm{min}$. crude lipase whereas Aspergillus niger $13 \mathrm{~F}$ has $4.2 \mathrm{U} / \mathrm{mL} / \mathrm{min}$. after 4 days incubation at $30^{\circ} \mathrm{C}$. Potent fungi culture was identified by morphological, cultural, and molecular characteristics (18s rRNA gene sequence and phylogenetic analysis) revealed them as Penicillium griseofulvum 5F, Aspergillus flavus 6F, Fusarium solani 7F, Aspergillus niger 12F, Aspergillus niger 13F, and Aspergillus terreus 17F. Novelty: Fungi was the first time reported and isolated from cotton seed soapstock materials. In future studies, this enzyme will be used in the degradation of soapstock and also in the production of biosurfactant from soapstock.

Keywords: Cotton seed soapstock; Fusarium solani 7F; p-nitrophenyl palmitate; Tributyrin agar plates; degradation

\section{Introduction}

Lipases (triacylglycerol ester hydrolases E.C.3.1.1.3.) are one of the most important industrial enzymes catalyze both the hydrolysis and the synthesis of esters from 
glycerol and long-chain fatty acids. These enzymes, under specific condition to catalyze reversible reactions: interesterification, aminolysis and transesterification reactions ${ }^{(1,2)}$. Novel enzymes research of lipase may provide greater understanding of previously discovered enzymes and their functional significance using molecular tools that may be used as parts of the microbial pool for production of lipase in research at laboratory and industries level ${ }^{(3)}$. Research aspects, reported lipase producing fungi were Humicolal anuginosa ${ }^{(4)}$, Fusarium sp. ${ }^{(5-7)}$, Mucor sp. ${ }^{(8)}$, Aspergillus sp. ${ }^{(9,10)}$ Rhizopus oryzae ${ }^{(6,11)}$, Colletotrichum gloeosporioides $^{(12)}$, Alternaria dianthicola, Curvularia sp., Penicillium sp., Trichoderma viridae, Macrophomina phaseolina ${ }^{(6)}$, Hypocrea pseudokoningii ${ }^{(13)}$ etc. Lipases are a ubiquitous enzyme that is found widely in a variety of natural sources industrial wastes, vegetables oil processing factories, soil contamination with oil, etc ${ }^{(14)}$. Lipid is a large constituent of the earth's biomass and has its application in various industries like in detergents, dairy and textile, production of surfactants, oil processing and biodiesel of microbial origin ${ }^{(15,16)}$.

Cotton is a source of fiber, oil and protein. Oil-rich seeds are the vigor of pathogenic fungi in the process of biodeterioration of seed may be related to their degree of lipase production ${ }^{(6)}$. Soapstock is a gelatinous dark brown undesirable chemical compound which is separated from the oil refinery ${ }^{(17)}$. Soapstock will account for higher values for 5 to $10 \%$ of the crude oil mass and high concentration of free fatty acids and these byproducts use for fungal lipase production in SSF Aspergillus niger ${ }^{(18)}$. Soapstock from alkali refining is a source of fatty acids, but it also presents a handling, storage, and disposal problem. It is generated at a rate of $\sim 6 \%$ of the volume of crude soybean oil caustic refined ${ }^{(19)}$.

The production process, oils from agro-industrial waste can come forward as efficient enzymes inductor reducing the production cost. Additionally, this process can reduce environmental problems related to agro-industrial disposal ${ }^{(20)}$. Screening for new microorganisms and their lipolytic enzyme will open simple routes for synthetic processes and consequently new and faster ways to solve environmental problems. In this regard, the biotechnological process that can added value to waste by biodiesel production via lipase enzyme esterification ${ }^{(21,22)}$. On other hands microbial treatment to soapstock, Staphylococcus sp. strain produced biosurfactants and extracellular lipase, when soapstock was used as an alternative carbon source. These potent metabolic product biosurfactant and lipolytic enzymes were potentially applicable in soap stock treatment ${ }^{(23)}$. Pseudomonas aeruginosa strain was utilized Soybean oil soapstock as the sole carbon source for the production of rhamnolipids ${ }^{(24)}$. Candida antarctica and Candida apicola were produced glycolipids when supplemented with soapstock ${ }^{(25)}$. Oospora lactis fungi utilized cotton oil soapstock as carbon source and produced lipase enzyme. During fungi cultivation on soapstock, enzymatically hydrolysis of fat was taken place on the approach of biological alteration of cotton oil soap stock ${ }^{(26)}$. Lipase producing fungal strains, Aspergillus, Penicillium, Trichoderma and Mucor were isolated from palm oil mill effluent composts ${ }^{(27)}$. Where Lipase producing Bacillus licheniformis and Bacillus pumilus were isolated from cotton soapstock which will used in enzymatic degradation of soapstock ${ }^{(28)}$. Lipase produced by $F$. solani isolated from leaves decomposed in an aquatic environment has great potential to application in biodiesel production by transesterifcation of vegetable oils, as well as food industries in the production of fatty acid esters by hydrolysis and esterifcation. In the present study, maximum lipase activity was achieved by Fusarium solani using cotton oil as substrate and there is no any work related to isolation of lipolytic fungi by using cotton soapstock as a natural source.

This study was conducted to isolate lipase producing fungi that were enriched and screened on tributyrin agar plates. Culture was further analyzed for cellulase and protease production by plate assay. The fungal strain was identified on the basis of morphological characteristics and molecular 18s RNA sequence (Genetic Characterization) of the cultures using manual partial gene sequencing. In future study lipase will used in degradation of soapstock and produce industrially important products.

\section{Materials and Methods}

\subsection{Sample collection}

Lipolytic fungal strains were isolated from cotton seed Soapstock samples collected from different cotton seed oil refinery industries situated at Kadi (North Gujarat), India. All the soapstock samples were collected at the site of Washer discharge end of the pipe in sterile containers.

\subsection{Enrichment process of Soapstock sample}

For enrichment $\mathrm{B} / \mathrm{H}$ (Bushnell-Haas) medium was used ${ }^{(29-31)} .10$ grams of Cotton seed oil soapstock samples were enriched in $100 \mathrm{ml}$ of $\mathrm{B} / \mathrm{H}$ mediums for the growth of microbes. Broths were incubated at $30^{\circ} \mathrm{C}$ in static condition for 5 days. From each enriched samples, $1 \mathrm{ml}$ of samples were inoculated to $100 \mathrm{ml}$ of the Trybutyrine broth medium. TBA broth was incubated at $30^{\circ} \mathrm{C}$, in static condition for 48 hours. Enrichment was performed over 7 days of incubation. 


\subsection{Isolation of Lipolytic Fungi}

For isolation of fungi, A series of dilutions from $10^{-1}$ to $10^{-10}$ were prepared from enriched sample. These dilutions were used in spread plate method. The diluted samples $(100 \mu \mathrm{l})$ were pipette and spread on Tributyrin agar plate and incubated at $30^{\circ} \mathrm{C}$ for 7 days. Isolated fungal colonies were sub-cultured and purified on the TBA medium. Isolated cultures were preserved at $4^{\circ} \mathrm{C}$ temperatures in Potato dextrose agar slants for further works.

\subsection{Qualitative screening of Lipase producing fungi}

For screening, Qualitative plate assay was performed according to the method reported earlier for lipase-producing strains selection ${ }^{(31)}$. Isolates plugs were inoculated on tributyrin agar plates and incubated at $30^{\circ} \mathrm{C}$ for 5 days. The clear zone was observed due to the hydrolysis of tributyrin by lipase.

\subsection{Lipase enzyme assay}

\subsubsection{The composition of production medium for Lipase enzyme}

In $250 \mathrm{ml}$ Conical flask $100 \mathrm{ml}$ of production medium ${ }^{(31)}$ were prepared for fungal culture. Production medium for lipase contain $0.5 \%$ Peptone, $0.5 \%$ Yeast extract, $0.5 \% \mathrm{NaCl}, 1 \%$ Cottonseed Oil, pH-7.

\subsubsection{Quantitative analysis of Lipase enzyme under submerge fermentation}

Fungal cultures that showed Positive lipase production in plate assay were subjected to quantitative analysis. 5 days old cultures grown on the TBA medium were used for inoculation. Two plugs of fungal culture were inoculated into $100 \mathrm{ml}$ of production medium for lipase production. Cultures were incubated at $30^{\circ} \mathrm{C}$ and $100 \mathrm{rpm}$ for 5 days. The enzyme assay was performed according to the method reported by Patel and Shah, $2018^{(32)}$. The culture filtrate was removed from each flask at every $24 \mathrm{hrs}$ interval and centrifuged at $10,000 \mathrm{rpm}$ for $10 \mathrm{~min}$ at $40^{\circ} \mathrm{C}$. Supernatant were used for enzyme assay. By using p-nitro phenyl palmitate (p-NPP) as a substrate, lipase production was determined by a spectrophotometric assay. Lipase hydrolyzed p-NPP to give $\mathrm{p}$-NP which gave yellow color and absorbance of which was measured spectrophotometrically at $410 \mathrm{~nm}$ against enzyme free blank.

\subsubsection{Assay of enzyme}

The substrate solution preparation: solution A ( $40 \mathrm{mg}$ of p-NPP dissolved in $12 \mathrm{ml}$ isopropanol) and solution B ( $0.1 \mathrm{~g}$ of gum Acasia and $0.4 \mathrm{ml}$ of triton X-100 dissolved in $90 \mathrm{ml}$ of distilled water). The substrate solution was prepared by adding $1 \mathrm{ml}$ of solution A to $19 \mathrm{ml}$ of solution B drop wise with constant stirring to obtain an emulsion that remains stable for $2 \mathrm{~h}$. The assay

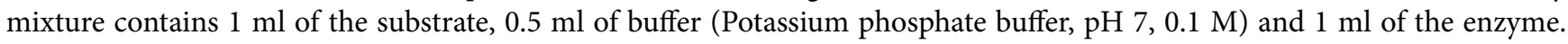
The volume was made up to $4 \mathrm{ml}$ with distilled water. Incubate at RT for $5 \mathrm{~min}$. Lipase activity was stopped by adding $1 \mathrm{ml}$ $0.2 \mathrm{M} \mathrm{NaOH}$. Lipase activity was measured by monitoring the hydrolysis of $5 \mathrm{mM}$ p-nitro phenyl palmitate (pNPP) buffered with $0.1 \mathrm{M}$ Potassium Phosphate buffer ( $\mathrm{pH} 7.0$ ) at $410 \mathrm{~nm}$ for $5 \mathrm{~min}$. One unit of lipase enzyme activity defined as $1 \mathrm{mM}$ of $\mathrm{p}$-NP liberated per min under the assay conditions.

\subsection{Enzyme profile}

Qualitative screening for Cellulase and Protease were done in nutrient agar media containing $1 \%$ carboxy methyl cellulose and $1 \%$ skim milk substrates respectively. Culture plug was inoculated and incubated at $30^{\circ} \mathrm{C}$ for 5 days. Zone of clearance was observed around the colonies due to the utilization of the particular substrate.

\subsubsection{For Cellulolytic activity}

As per method performed earlier ${ }^{(3)}$, culture were grown in medium containing $1 \%$ carboxy methyl cellulose. After incubation $0.1 \%$ congo red staining solution was added in CMC plates, discard stain after $5 \mathrm{~min}$ and the plates were destained by $1 \mathrm{M} \mathrm{NaCl}$ solution with continuous stirring for 15-20 min. The clear zone around colonies indicated cellulose hydrolysis.

\subsubsection{For Proteolytic activity}

$1 \%$ skim milk substrate containing nutrient agar media were used for screening of protease ${ }^{(33)}$. Culture plugs was inoculated and incubated at $30^{\circ} \mathrm{C}$ for 5 days and observed for clear zone around colonies due to protein hydrolysis. 


\subsection{Identification of the fungal isolates: morphological and molecular characteristics}

The potent isolates showing the maximum zone of clearance were selected for further analysis. On potato dextrose agar medium, morphological and cultural characteristics of the isolates were studied such as the color of hyphae, type of hyphae, shape and the characteristics of spore, using microscopic examination. Molecular characterization of potent fungal strains was done by $18 \mathrm{~s}$ rRNA partial gene sequencing analysis. It was carried out at the Biogene department of Gujarat State Biotechnology Mission (GSBTM), Gandhinagar. Fungi culture isolates were identified through partial gene ITS region sequence and 18S rRNA sequence using ITS 1/ITS 4 primer. The 18S rRNA gene sequence was used to carry out BLAST with the nr database of NCBI gene bank database. Based on maximum identity score first ten sequences were selected and aligned using multiple alignment software program Clustal W. Distance matrix was generated using the RDP database and the phylogenetic tree was constructed using MEGA X.

\subsection{Statistical analysis}

In all experiments, three sets of reading were taken. Data, where appropriate, were subjected to two- way analysis of variance (ANOVA) followed by Tukey's multiple comparison test and student's test using Graph Pad Prism 8.3.1 (GraphPad Software Inc., San Diego, CA, USA). Quantitative analysis of lipase production were plotted using Graph-Pad Prism 8.3.1, Significance was accepted at $\mathrm{p}<0.05$.

\section{Results and discussion}

\subsection{Sample collection}

Samples were collected from two oil refinery industries, Uma oil refinery industry, Kadi (North Gujarat), India \& Mahakali oil refinery industry, Karannagar (North Gujarat), India.

\subsection{Qualitative screening and isolation of lipolytic fungi}

A total of 49 pure cultures were isolated from enriched soapstock samples. Among these, 19 cultures were fungal isolates. The fungal cultures were further subjected to the qualitative screening on tributyrin agar medium to select lipolytic strain. The clear zone around fungal isolates exhibited on tributyrine agar plates within 5 days indicates positive results. Range of 5.30 to 35.00 $\mathrm{mm}$ of clear zone of lipid hydrolysis was observed by lipase producing isolates. However, only six isolates that showed good zone of lipid hydrolysis in diameter ranged between 13.30 to $35.00 \mathrm{~mm}$ were selected for further study and results were represented ( Table 1, Figure 1). Among the six fungal strains, 7F isolate was detected to produce maximum zone of hydrolysis $(35.00 \mathrm{~mm})$, whereas $12 \mathrm{~F}$ isolate was produced minimum zone hydrolysis $(13.30 \mathrm{~mm})$ on $1 \%$ tributirine agar plates.

Table 1. Qualitative enzyme activity measure in clear zone diameter to colony diameter ratio of fungal isolates.

\begin{tabular}{lllll}
\hline \multirow{2}{*}{ Sr.no } & \multirow{2}{*}{ Fungal Isolates } & \multicolumn{2}{c}{ Clear zone diameter ratio $(\mathrm{mm})$} \\
\cline { 3 - 5 } & & Lipase activity & Cellulase Activity & Protease Activity \\
\hline 1 & $5 \mathrm{~F}$ & $16.00 \mathrm{~mm}$ & $10.34 \mathrm{~mm}$ & $08.68 \mathrm{~mm}$ \\
2 & $6 \mathrm{~F}$ & $19.70 \mathrm{~mm}$ & $13.29 \mathrm{~mm}$ & $11.90 \mathrm{~mm}$ \\
3 & $7 \mathrm{~F}$ & $35.00 \mathrm{~mm}$ & $29.10 \mathrm{~mm}$ & $15.00 \mathrm{~mm}$ \\
4 & $12 \mathrm{~F}$ & $13.30 \mathrm{~mm}$ & $09.00 \mathrm{~mm}$ & $07.39 \mathrm{~mm}$ \\
5 & $13 \mathrm{~F}$ & $20.00 \mathrm{~mm}$ & $17.90 \mathrm{~mm}$ & $14.17 \mathrm{~mm}$ \\
6 & $17 \mathrm{~F}$ & $16.30 \mathrm{~mm}$ & $13.37 \mathrm{~mm}$ & $10.00 \mathrm{~mm}$ \\
\hline
\end{tabular}




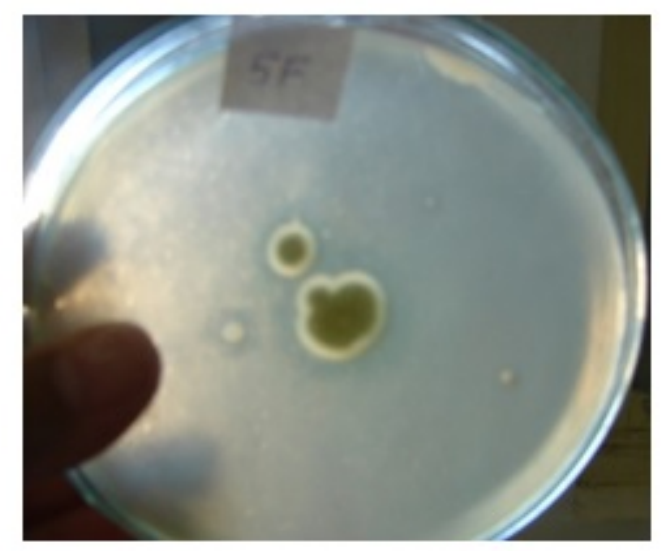

Culture Code 5F

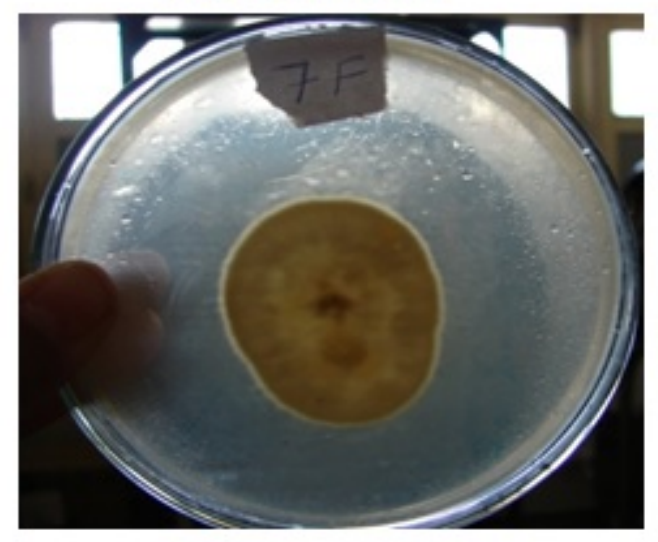

Culture Code 7F

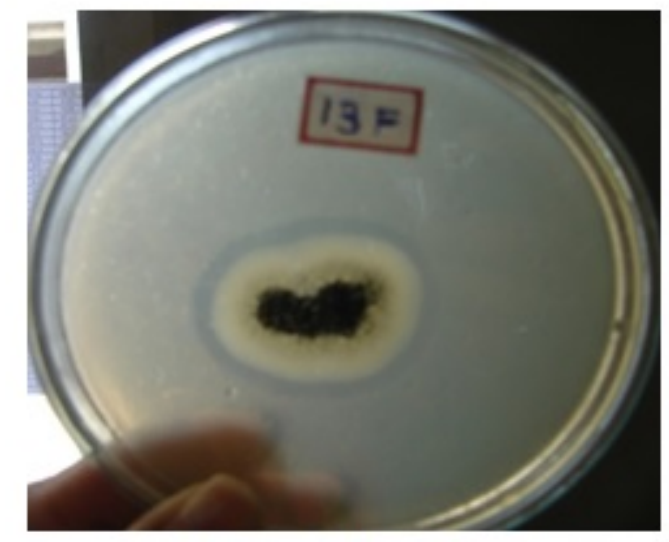

Culture Code 13F
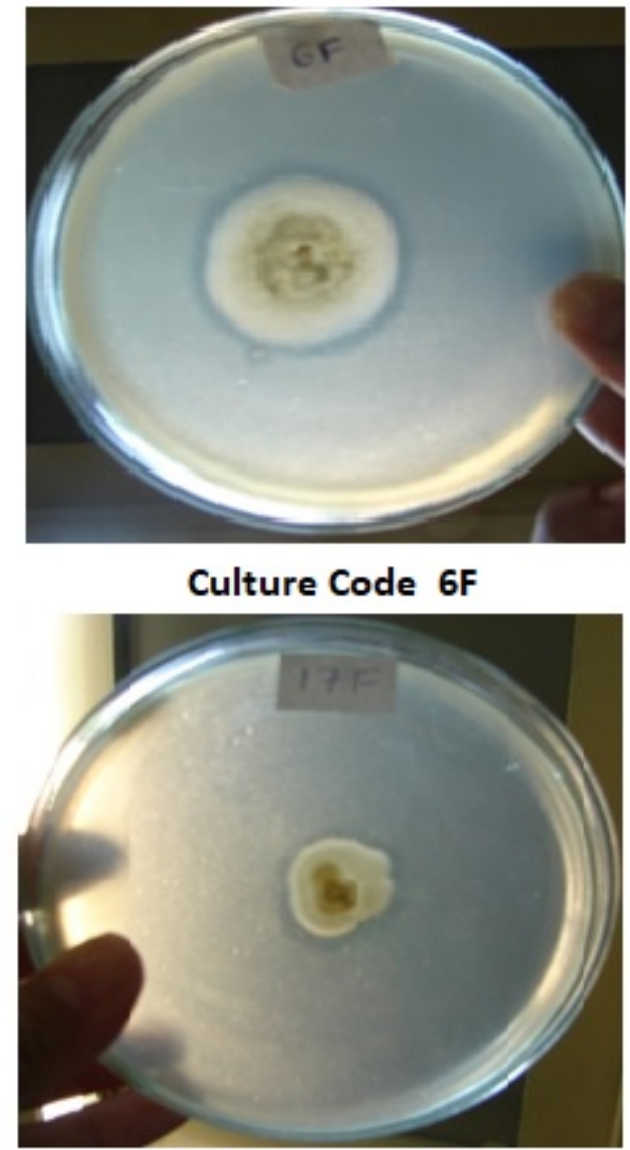

Culture Code $12 \mathrm{~F}$

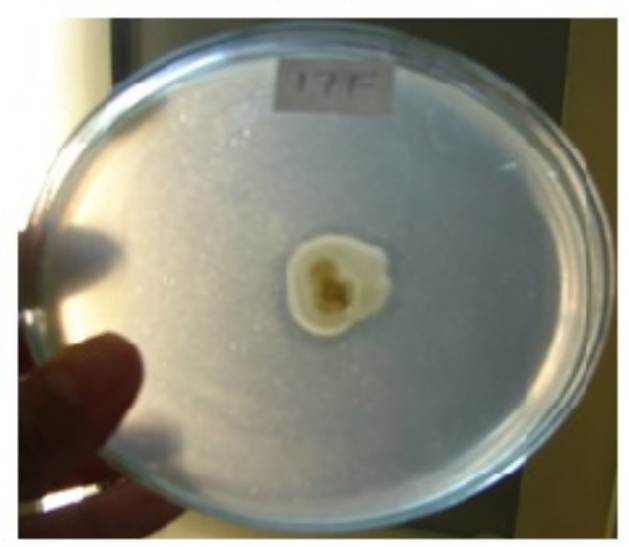

Culture Code $17 \mathrm{~F}$

Fig 1. Qualitative screening of Lipase production by fungal cultures on $1 \%$ tributyrin agar plate 


\subsection{Quantitative analysis of Lipase enzyme under submerges fermentation}

Agro-industrial wastes can easily be degraded by filamentous fungi, when synthesizing industrially important bio-compounds, such as lipolytic enzymes ${ }^{(34)}$. It is known that various fats, fatty acids, plant oils, triglycerides, ester-based detergents, and other substances are the best inducers of lipase synthesis by microorganisms and sources of carbon ${ }^{(35)}$. From earlier reported result Aspergillus species were used oils from agro-industrial waste (grape seed oil (GSO) and cotton seed oil (CSO)) to enhance lipase production further higher percentage of fatty acid esters (>80\%), namely, soybean, olive, and GSO, promoted the highest lipase production ${ }^{(20)}$. Present study results supports the earlier report on use of cotton seed oil as carbon source to enhance lipase production by Penicillium melinii ${ }^{(35)}$ and Oospora lactis fungi utilized cotton oil soapstock ( oil richer) as carbon source and produced lipase enzyme ${ }^{(26)}$. Fusarium sp. are able to cause disease in plant growth stages ${ }^{(36,37)}$. In contrast they are good industrially important lipase producers. Growth of fungi was enhanced in the production medium supplemented with oil. High fungus mycelium, biomass and maximum crude lipase production were obtained on 4th day in submerged fermentation are comparable with the previous studies reported results on Aspergillus sp. strains ${ }^{(9)}$. The lipase producing strains Aspergillus spp. were more frequently present in palm oil mill effluent composts and were isolated from it ${ }^{(27)}$.

Lipolytic strains were further quantitatively tested for crude lipase production by $\mathrm{p}$ - NPP as a substrate. In plate assay, shortlisted six fungal isolates were further screen for lipase production by submerged fermentation. The enzyme activities were performed by all six selected isolates. The six selected fungal isolates $(5 \mathrm{~F}, 6 \mathrm{~F}, 7 \mathrm{~F}, 12 \mathrm{~F}, 13 \mathrm{~F}$ and $17 \mathrm{~F})$ were examined for lipase production after $120 \mathrm{hrs}$ cultivation in $100 \mathrm{~mL}$ liquid medium supplemented with $1 \%$ cotton seed oil as a substrate. In previously reported F. solani was isolated from decomposition of leaves in an aquatic environment, shown lipase production when utilizing Cotton oil as a carbon source in submerged condition ${ }^{(28)}$. Similar result was obtained; Fusarium solani $7 \mathrm{~F}$ fungi produced lipase in presence of cotton seed oil in submerged fermentation. The activities ranged from 2.1 to $5.9 \mathrm{U} / \mathrm{mL} / \mathrm{min}$ for lipase. From the observation, the 7F isolate exhibited the highest lipase activities, $5.9 \mathrm{U} / \mathrm{mL} / \mathrm{min}$ than that the others. The lipase activities were shown by individual fungal isolates at different time period ( Figure 2 ). $7 \mathrm{~F}$ fungi showed maximum lipase activity 5.95 $\mathrm{U} / \mathrm{ml} / \mathrm{min}$ in submerged fermentation when incubated at $30^{\circ} \mathrm{C}$ at $\mathrm{pH}$. The activity of $7 \mathrm{~F}$, when compared to other fungi was highly significant $(\mathrm{p}<0.0001)$ at a time interval of $24 \mathrm{hrs}$. Lipase activity $(5.92 \mathrm{U} / \mathrm{mL} / \mathrm{min})$ of $7 \mathrm{~F}$ was obtained maximum compare to lipase activity $(5.72 \mathrm{U} / \mathrm{mL} / \mathrm{min})$ of $M u c o r{ }^{(27)}$.

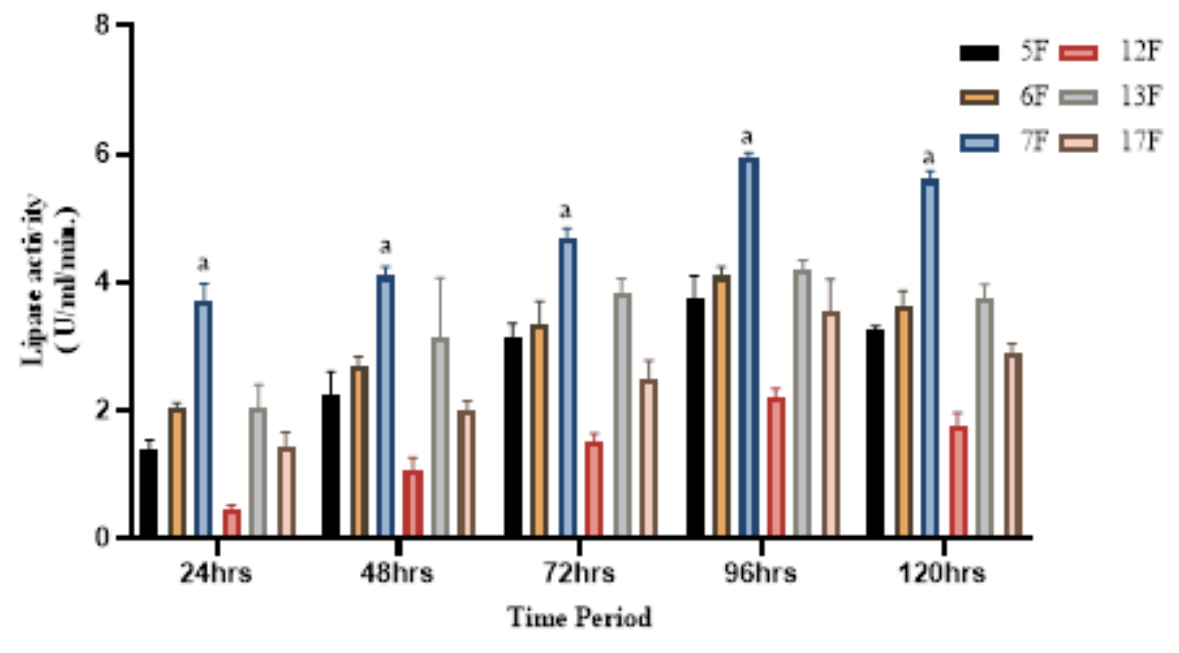

Fig 2. Time course study of different fungal isolates. ANOVA: $\mathrm{p}$ value $=\mathrm{p}<0.0001$, $\mathrm{p}$ value summary based on Tukey's multiple comparison tests $=$ a highly significant at a time interval of $24 \mathrm{hrs}$.

\subsection{Enzyme profile}

Fungi cultures were further screened for Cellulase and Protease activity by plate assay. Their cellulase and protease activity were detected by clear zone formation on CMC and milk agar plate respectively within 5 days and results were represented ( Table 1 ). All six isolates showed positive result for cellulase and protease activity in plate assay. Among the six fungal strains, $7 \mathrm{~F}$ isolate 
was detected to produce maximum zone of hydrolysis $(29.10 \mathrm{~mm})$ on $1 \%$ carboxy- methyl cellulose agar plate, whereas $7 \mathrm{~F}$ isolate was also detected to produce maximum zone hydrolysis $(15.00 \mathrm{~mm})$ on $1 \%$ skim milk agar plate.

\subsection{Characterization of Fungal Isolates}

The fungal isolates which showed the maximum zone of clearance for lipase production were subjected to further characterization and identification. The morphological and cultural characteristics of Fusarium solani were the same as those reported in previous work ${ }^{(36)}$. Growth characteristics of the Fusarium solani 7F isolate on PDA plate were white mycelia, which spread very fast, hyphae branched and septate. Fusarium solani 7F grows radials and spores produced. Yellowish pigments appear on the back of the plate. Penicillium griseofulvum 5F fungi isolate grow slowly, mycelia green cottony and back of plate yellow pigment. Aspergillus flavus $6 \mathrm{~F}$ culture mycelium spread fast, mycelia white initially after three days incubation macro spore turn green and back of plate no pigment. Zone observed in two parts white to green centre. Aspergillus niger $12 \mathrm{~F}$ fungus moderately grows on PDA, mycelia white cottony and no pigment observed. Aspergillus niger 13F isolate growth very fast, mycelia white initially on aging macro spore turn black and back of plate no pigment. Zone observed in two parts white to black centre. Aspergillus terreus $17 \mathrm{~F}$ culture growth was fast, mycelia initially white after three days incubation macro spore turns brown. Zone observed in two parts white to brown centre. Potent fungi culture was identified by morphological, cultural and molecular characteristics culture 5F, 6F, 7F, 12F, 13F and 17F were identified as Penicillium griseofulvum, Aspergillus flavus, Fusarium solani, Aspergillus niger, Aspergillus niger and Aspergillus terreus respectively ( Figure 3). The sequence of the gene deposited at the NCBI repository is accessible by Accession numbers ( Table 2 ). The Phylogenetic tree was created with maximum likelihood methods and Tamura-Nei model shows evolutionary history of deposited sequence with other aligned sequence. The bootstrap consensus tree inferred from 500 replicates is taken to represent the evolutionary history of the taxa analyzed. Branches corresponding to partitions reproduced in less than $50 \%$ bootstrap replicates are collapsed. The percentage of replicate trees in which the associated Taxa clustered together in the bootstrap test (500 replicates) was shown next to the branches. Initial tree(s) for the heuristic search were obtained automatically by applying Neighbor-Join and BioNJ algorithms to a matrix of pair wise distances estimated using the Maximum Composite Likelihood (MCL) approach, and then selecting the topology with superior log likelihood value. Evolutionary analyses were conducted in MEGA X ( Figure 4 ). Reported fungal strains such as Aspergillus flavus, Aspergillus niger and Aspergillus terreus showed the degradation of crude oil due to the production of extracellular enzymes ${ }^{(38)}$.

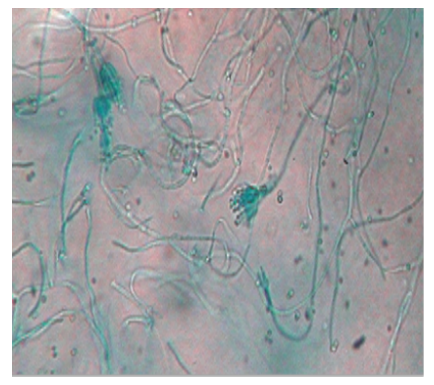

Culture Code $5 \mathrm{~F}$

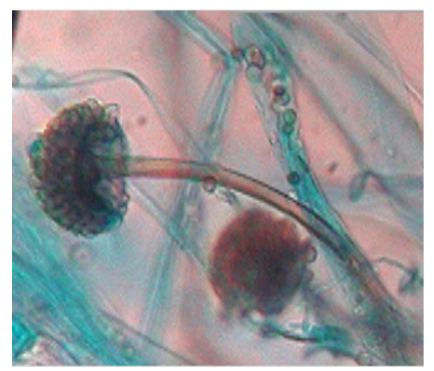

Culture Code $12 \mathrm{~F}$

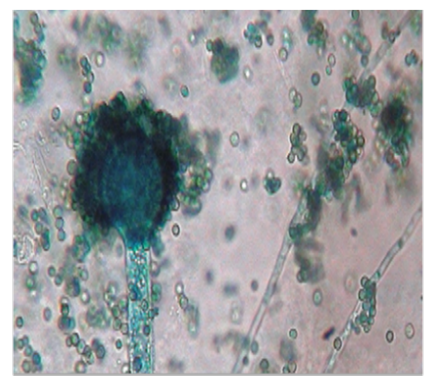

Culture Code 6F

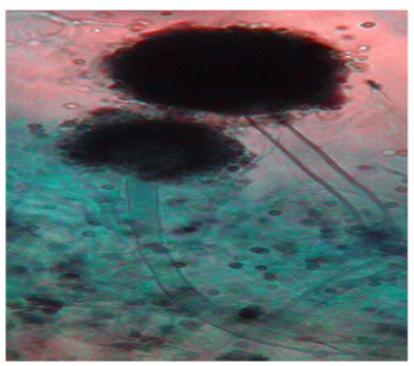

Culture Code $13 \mathrm{~F}$

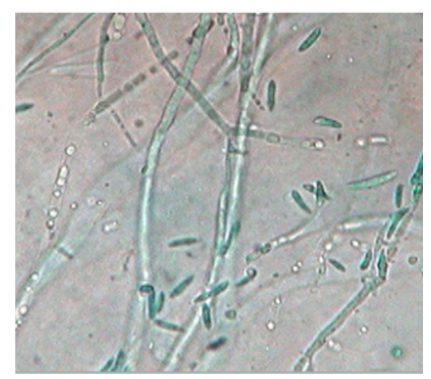

Culture Code 7F

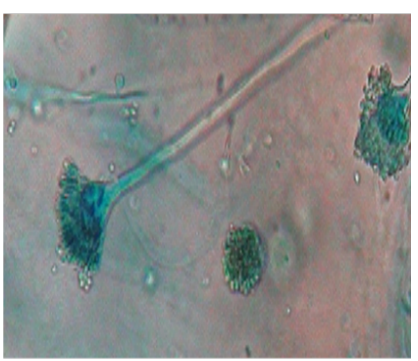

Culture Code 17F

Fig 3. Microscopic observation of isolated fungi 
Table 2. Accession number of isolated Fungi

\begin{tabular}{llll}
\hline Sr.no & Culture code & Accession number & Organism \\
\hline 1 & $5 \mathrm{~F}$ & MN749934 & Penicillium griseofulvum \\
2 & $6 \mathrm{~F}$ & MN750585 & Aspergillus flavus \\
3 & $7 \mathrm{~F}$ & MH571778 & Fusarium solani \\
4 & $12 \mathrm{~F}$ & MN750583 & Aspergillus niger \\
5 & $13 \mathrm{~F}$ & MH571779 & Aspergillus niger \\
6 & $17 \mathrm{~F}$ & MN750586 & Aspergillus terreus \\
\hline
\end{tabular}

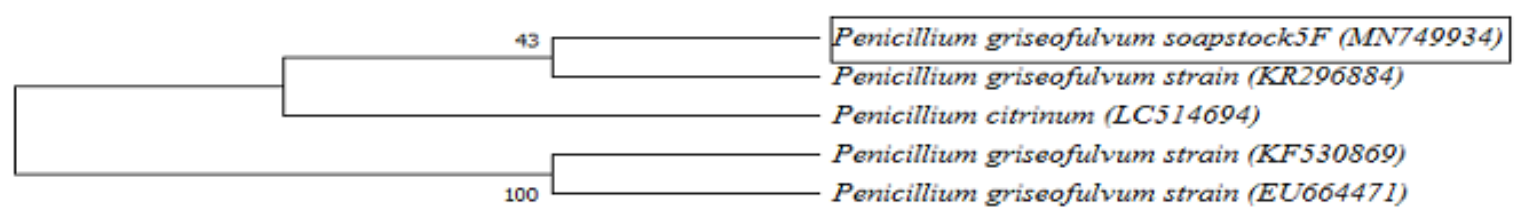

Figure 4a. Phylogenetic tree of Penicillium griseofulvum soapstock5F (MN749934)

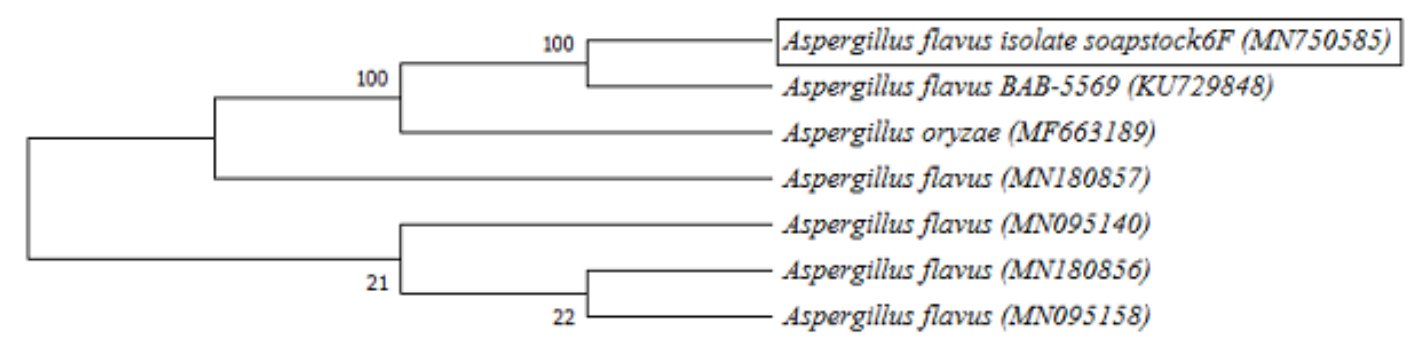

Figure 4b. Phylogenetic tree of Aspergillus flavus soapstock 6F (MN750585)

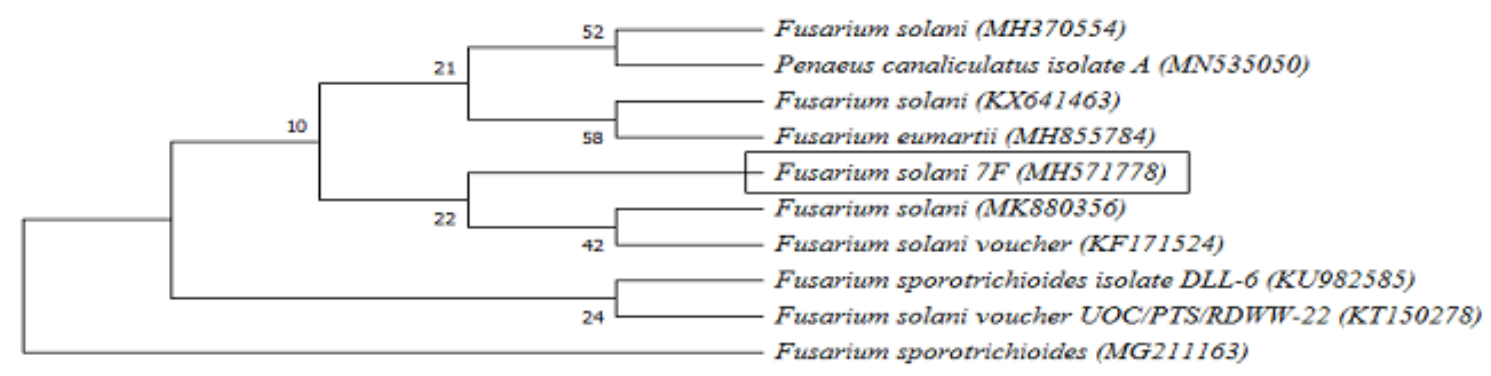

Figure 4c. Phylogenetic tree of Fusarium solani 7F (MH571778)

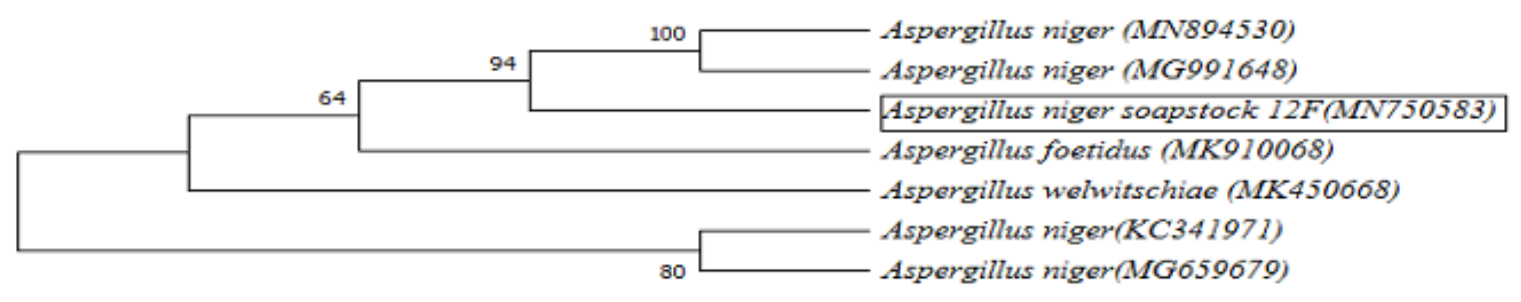

Figure 4d. Phylogenetic tree of Aspergillus niger soapstock 12F (MN750583)

Fig 4. 


\section{Conclusion}

Cotton seed soapstock samples were collected from the oil refinery industry for the isolation \& screening extracellular lipase producing micro-organisms. 49 isolates including bacteria $\&$ fungi were screened. The isolates showed highest lipase production in plate assays were further quantitatively tested for production of lipase by pNPP as substrate assay. The isolated microorganisms have higher ability to produce lipase enzyme. In further studies pilot scale lipase production and its purification studies will be conducted. Enzyme derived from Fusarium solani 7F is further used in the microbial degradation of soapstock and production of biosurfactant. The identified cultures were deposited in the NCBI culture collection center with accession number.

\section{Acknowledgements}

The authors are thankful to the Department of Biotechnology, Pramukh Swami Science and H.D. Patel Arts College, KSV, I for providing facilities to carry out research. The authors also wish to express thanks to Gujarat State Biotechnology Mission at Gandhinagar, India for the valuable advices in the identification of the Fungi isolates.

\section{References}

1) Santos RRD, Muruci LNM, Santos LO, Antoniassi R, da Silva JPL, Damaso MCT. Characterization of Different Oil Soapstocks and Their Application in the Lipase Production by Aspergillus niger under Solid State Fermentation. Journal of Food and Nutrition Research. 2014;2(9):561-566. Available from: https://dx.doi.org/10.12691/jfnr-2-9-6.

2) Farias M, Valoni E, Castro A, Coelho MA. Lipase production by yarrowia lipolytica in solid state fermentation using different agro industrial residues. Chemical engineering transactions. 2014;38:301-306. Available from: http://doi.org/10.3303/CET1438051.

3) Dabhi BK, Vyas RV, Shelat HN. Use of Banana Waste for the Production of Cellulolytic Enzymes under Solid Substrate Fermentation Using Bacterial Consortium. International Journal of current Microbiology and Applied Science. 2014;3(1):1-9. Available from: http://www.ijcmas.com.

4) Arima K, Liu WH, Beppu TK, Liu WH, Beppu T. Isolation and Identification of the Lipolytic and Thermophilic Fungus. Agricultural and Biological Chemistry. 1972;36(11):1913-1917. Available from: https://doi.org/10.1080/00021369.1972.10860507.

5) Prazeres JND, Cruz JAB, Pastore GM. Characterization of alkaline lipase from Fusarium oxysporum and the effect of different surfactants and detergents on the enzyme activity. Brazilian Journal of Microbiology. 2006;37(4):505-509. Available from: https://dx.doi.org/10.1590/s1517-83822006000400019.

6) Kakde RB, Chavan AM. Extracellular Lipase Enzyme Production by Seed-Borne Fungi under the Influence of Physical Factors. International Journal of Biology. 201020;3(1):94-100. Available from: http://www.ccsenet.org/journal/index.php/ijb/article/view/7020doi:10.5539/ijb.v3n1p94.

7) Mase T, Matsumiya Y, Akiba T. Purification and Characterization of a New Lipase fromFusariumsp. YM-30. Bioscience, Biotechnology, and Biochemistry. 1995;59(9):1771-1772. Available from: https://dx.doi.org/10.1271/bbb.59.1771.

8) Alves MH, Campos-Takaki MG, Porto ALF, Milanez AI. Screening of Mucor spp. for the production of amylase, lipase, polygalacturonase and protease. Brazilian Journal of Microbiology. 2002;33(4):325-330. Available from: https://dx.doi.org/10.1590/s1517-83822002000400009.

9) Cihangir N, Sarikaya E. Investigation of lipase production by a new isolate of Aspergillus sp. World Journal of Microbiology and Biotechnology. 2004;20(2):193-197. Available from: https://dx.doi.org/10.1023/b:wibi.0000021781.61031.3a.

10) Wadia T, Jain SK. Isolation, Screening and Identification of Lipase Producing Fungi from Oil Contaminated Soil of Shani Mandir Ujjain. International Journal of Current Microbiology and Applied Sciences. 2017;6(7):1872-1878. Available from: https://dx.doi.org/10.20546/ijcmas.2017.607.223.

11) Salah RB, Mosbah H, Fendri A, Gargouri A, Gargouri Y, Mejdoub H. Biochemical and molecular characterization of a lipase produced by Rhizopus oryzae. FEMS Microbiology Letters. 2006;260(2):241-248. Available from: https://dx.doi.org/10.1111/j.1574-6968.2006.00323.x.

12) Balaji V. Optimization of extracellular lipase production in Colletotrichum gloeosporioides by solid state fermentation. Indian Journal of Science and Technology. 2008;1(7):1-8. Available from: https://dx.doi.org/10.17485/ijst/2008/vli7.11.

13) Pereira MG, Vici AC, Facchini FDA, Tristão AP, Cursino-Santos JR, Sanches PR, et al. Screening of filamentous fungi for lipase production:Hypocrea pseudokoningiia new producer with a high biotechnological potential. Biocatalysis and Biotransformation. 2014;32(1):74-83. Available from: https: //dx.doi.org/10.3109/10242422.2013.873417.

14) Roy M, Kumar R, Ramteke A, Sit N. Identification Of lipase producing fungus isolated from dairy waste contaminated soil and optimization Of culture conditions for Lipase production by the Isolated fungus. Journal of Microbiology, Biotechnology and Food Sciences. 2018;8(1):698-704. Available from: https://dx.doi.org/10.15414/jmbfs.2018.8.1.698-704.

15) Sharma R, Chisti Y, Banerjee UC. Production, purification, characterization, and applications of lipases. Biotechnology Advances. 2001;19(8):627-662. Available from: https://dx.doi.org/10.1016/s0734-9750(01)00086-6.

16) Verma N, Thakur S, Bhatt AK. Microbial Lipases: Industrial Applications and Properties (A Review). International Research Journal of Biological Sciences. 2012;1(8):88-92. Available from: http://www.isca.me/IJBS/Archive/v1/i8/15.ISCA-IRJBS-2012-180.pdf.

17) King WJ, Taylor LS, Snyder MJ, Holliday LR. Total fatty acid analysis of vegetable oil soapstocks by supercritical fluid extraction/reaction. Journal of the American Oil Chemists' Society. 1998;75(10):1291-1295. Available from: https://dx.doi.org/10.1007/s11746-998-0174-9.

18) Santos RRD, Muruci LNM, Santos LO, Antoniassi R, da Silva JPL, Damaso MCT. Characterization of Different Oil Soapstocks and Their Application in the Lipase Production by Aspergillus niger under Solid State Fermentation. Journal of Food and Nutrition Research. 2014;2(9):561-566. Available from: https://dx.doi.org/10.12691/jfnr-2-9-6.

19) O'brien RD. Soybean Oil Purification. In: Johnson AL, White JP, Galloway R, editors. Soybeans. Elsevier. 2008;p. 377-408. Available from: https://doi: 10.1016/b978-1-893997-64-6.50015-9.

20) Tacin MV, Massi FP, Fungaro MHP, Teixeira MFS, de Paula AV, de Carvalho Santos-Ebinuma V. Biotechnological valorization of oils from agroindustrial wastes to produce lipase using Aspergillus sp. from Amazon. Biocatalysis and Agricultural Biotechnology. 2019;17:369-378. Available from: https://dx.doi.org/10.1016/j.bcab.2018.11.013. 
21) Wang Y, Cao X. Enzymatic synthesis of fatty acid ethyl esters by utilizing camellia oil soapstocks and diethyl carbonate. Bioresource Technology. 2011;102(22):10173-10182. Available from: https://linkinghub.elsevier.com/retrieve/pii/S0960852411012715.

22) Botton V, Piovan L, Meier HF, Mitchell DA, Cordova J, Krieger N. Optimization of biodiesel synthesis by esterification using a fermented solid produced by Rhizopus microsporus on sugarcane bagasse. Bioprocess and Biosystems Engineering. 2018;41(4):573-583. Available from: https://dx.doi.org/10.1007/ s00449-018-1892-5.

23) Cherif S, Mnif S, Hadrich F, Abdelkafi S, Sayadi S. Strategy for improving extracellular lipolytic activities by a novel thermotolerant Staphylococcus sp. strain. Lipids in Health and Disease. 2011;10(1):209-209. Available from: https://dx.doi.org/10.1186/1476-511x-10-209.

24) Nitschke M, Costa SGVAO, Contiero J. Structure and Applications of a Rhamnolipid Surfactant Produced in Soybean Oil Waste. Applied Biochemistry and Biotechnology. 2010;160(7):2066-2074. Available from: https://dx.doi.org/10.1007/s12010-009-8707-8.

25) Bednarski W, Adamczak M, Tomasik J, Płaszczyk M. Application of oil refinery waste in the biosynthesis of glycolipids by yeast. Bioresource Technology. 2004;95(1):15-18. Available from: https://dx.doi.org/10.1016/j.biortech.2004.01.009.

26) Kd D, Ka G, Bkh A, Nm T. Enzymatic utilization of cotton soap stock. Prikladnaia Biokhimiia i Mikrobiologiia. 2000;36(1):26-35. Available from: https://europepmc.org/article/med/10752080.

27) Nwuche CO, Ogbonna JC. Isolation of lipase producing fungi from palm oil mill effluent (POME) dump sites at Nsukka. Brazilian Archives of Biology and Technology. 2011;54(1):113-116. Available from: https://dx.doi.org/10.1590/s1516-89132011000100015.

28) Mendes DB, Silva FFD, Guarda PM, Almeida AF, de Oliveira DP, Morais PB, et al. Lipolytic Enzymes with Hydrolytic and Esterification Activities Produced by Filamentous Fungi Isolated from Decomposition Leaves in an Aquatic Environment. Enzyme Research. 2019;2019:1-13. Available from: https://dx.doi.org/10.1155/2019/8182425.

29) Gs G, Hr G, Mr P, Sk G, Vb B. Isolation and Enrichment of Microbes for Degradation of Crude Oil. International Journal of Engineering Science and Innovative Technology. 2013;2(4):144-147. Available from: https://www.researchgate.net/publication/259410073.

30) Mahmood MH, Yang Z. Bioremediation of disposed engine oil for Lipase production. In: and others, editor. FGIC 1st Conference on Governance \& Integrity. 2017;p. 337-354. Available from: https://core.ac.uk/download/pdf/159192703.pdf.

31) Patel BG, Shah RK. Biodegradation of cotton seed soapstocks by novel indigenous Bacillus species. Bioscience Biotechnology Research Communications. 2018;11(3):505-511. Available from: https://dx.doi.org/10.21786/bbrc/11.3/21.

32) Winkler UK, Stuckmann M. Glycogen Hyaluronate, and Some Other Polysaccharides Greatly Enhance the Formation of Exolipase by Serratia marcescenst. Journal Of Bacteriology. 1979;138(3):663-670. Available from: http://jb.asm.org/content/138/3/663.abstract.

33) Prabavathi R, Mathivanan V, Ambika A. Screening of Protease Enzyme by Construction Of Metagenomic Library From Marine Soil Sediments. International Journal of Pharma Sciences and Research. 2012;3(7):396-399. Available from: http://www.ijpsr.info/docs/IJPSR12-03-07-05.pdf.

34) Costa TM, Hermann KL, Garcia-Roman M, de Cassia Siqueira Curto Valle R, Tavares LBB. Lipase production by Aspergillus niger grown in different Agro-industrial wastes by solid-state fermentation. Brazilian Journal of Chemical Engineering. 2017;34(2):419-427. Available from: https://dx.doi.org/10. 1590/0104-6632.20170342s20150477.

35) Makhsumkhanov AA, Yakubov IT, Davranov K. Conditions for cultivation of the fungus Penicillium melinii UzLM-4 and Its biosynthesis of lipases. Applied Biochemistry and Microbiology. 2003;39(1). Available from: https://link.springer.com/article/10.1023/A:1021793809352.

36) Chimbekujwo IB. Frequency and pathogenicity of fusarium wilts (Fusarium solani and Fusarium equiseti) of cotton (Gossypium hirsutum) in Adamawa in Nigeria. Revista de BiologiaTropical. 2000;48(1):1-5. Available from: http://www.scielo.sa.cr/scielo.php?script=sci_serial\&pid=0034-7744\&lng=en\& $\mathrm{nrm}=\mathrm{iso}$.

37) Patel H, Suthar R, Shah K. Study of wilt producing Fusarium sp. from tomato (Lycopersicon esculentum Mill). International Journal of Current Microbiology and Applied Sciences. 2014;3(8):854-858. Available from: https://www.researchgate.net/publication/265511558.

38) Olukunle OF, Oyegoke TS. Biodegradation of crude-oil by fungi isolated from cow dung contaminated soils. Nigerian Journal of Biotechnology. 2016;31(1):46-46. Available from: https://dx.doi.org/10.4314/njb.v31i1.7. 